\title{
The effect of different neural mobilization exercises on hamstring flexibility and functional flexibility in wrestlers
}

\author{
Aydın Balcı', Ezgi Ünüvar², Bihter Akınoğlu ${ }^{2,3, *}$, Tuğba Kocahan² \\ 'Department of Sports Medicine, Yenimahalle Training and Research Hospital, Yildirim Beyazit University, Ankara, Turkey \\ ${ }^{2}$ Center of Athlete Training and Health Research, Department of Health Services, Sports General Directorship, The Ministry of Youth and Sports, Ankara, Turkey \\ ${ }^{3}$ Department of Physiotherapy and Rehabilitation, Faculty of Health Sciences, Ankara Yıldırım Beyazıt University, Ankara, Turkey
}

This study aimed to compare the short-term effects of sciatic nerve neural sliding and neural stretching exercises on hamstring muscle length and functional flexibility in wrestlers. The study participants included 74 wrestlers. The athletes were randomly divided into two groups: neural sliding and neural stretching groups. The hamstring flexibility and the functional flexibility were assessed using the active knee extension limitation (AKEL) angle and the sit and reach (SR) test one day before and immediately after the neural mobilization exercises, respectively. A three-way repeated measures analysis of variance was conducted that examined the effect of mobilization type, time, and gender on interest in AKEL right leg, AKEL left leg, and SR test. There is not a significant difference between the effect of two different mobilizations on AKEL right and left leg, and SR test $(P>0.05)$. It was determined there is statistically significant differences between premobilization and postmobilization outcome measures for AKEL right leg $(F=59.886, P=0.001)$, AKEL left leg ( $F=31.896, P=0.001)$, and $S R$ test $(F=22.630, P=0.001)$. There is not a statistically significant difference between males and females by these three measures neural sliding and neural stretching exercises to the sciatic nerve in wrestlers were effective in increasing hamstring flexibility and functional flexibility and not superior to each other.

Keywords: Wrestling, Shortness, Hamstring, Flexibility, Neural, Mobilization

\section{INTRODUCTION}

Wrestling is a sport that requires maximal strength and anaerobic power. In order to reveal the maximal muscle strength, the muscular components must be of optimal length. Decreased hamstring length and low flexibility in elite wrestlers are frequently observed (Callan et al., 2000). Decreased hamstring muscle length causes several musculoskeletal problems such as low back pain (Tafazzoli and Lamontagne, 1996), sacroiliac joint dysfunction (Arab et al., 2009), hamstring injuries (Heiderscheit et al., 2010), patellofemoral pain syndrome (Petersen et al., 2014), patellar tendinopathy (Van der Worp et al., 2011), and plantar fasciitis (Bahr and Holme, 2003).

Hamstring injuries are frequently seen in physically active individuals, especially in competition athletes such as wrestling (Park et al., 2019; Safran et al., 1988). Inadequate warming (Witvrouw et al., 2003), reduced flexibility (Croisier, 2004), muscle strength imbalances (Turl and George, 1998), neural tension (Kujala et al., 1997), fatigue (Verrall et al., 2001), and injury story (Davis et al., 2005) have been identified as risk factors for hamstring injuries. Lack of flexibility, especially in the hamstring, is the most commonly accepted risk factor for injury (Kornberg and Lew, 1989). Because reduced hamstring flexibility reduces neurodynamic functions and affects the physiological properties of neural tissue, this causes tonus problems in the hamstring muscle sensitivity to stretch and pain (Marshall et al., 2011). Thus, this mechanical sensitivity in neural tissues creates a ground for injuries by adversely affecting the functioning of protective mechanisms against muscle injury (Boyd et al., 2009; Hall et al., 1998).

Mobilization exercises applied to neural tissues are used as a
*Corresponding author: Bihter Akınoğlu (iD https://orcid.org/0000-0002-8214-7895 Department of Physiotherapy and Rehabilitation, Faculty of Health Sciences, Ankara Yildırım Beyazıt University, Ankara 05059384136, Turkey E-mail: rgkardelen@yahoo.com

Received: September 25, 2020 / Accepted: October 14, 2020
This is an Open Access article distributed under the terms of the Creative Commons Attribution Non-Commercial License (https://creativecommons.org/licenses/by-nc/4.0/) which permits unrestricted non-commercial use, distribution, and reproduction in any medium, provided the original work is properly cited. 
supportive method in the treatment of musculoskeletal injuries (De-la-Llave-Rincon et al., 2012; Hall et al., 1998). Neural mobilization exercises may reduce neural sensitivity to the movement and may be useful as an addition to rehabilitation programs to increase hamstring flexibility (De-la-Llave-Rincon et al., 2012; Hall et al., 1998).

Increasing the flexibility of the hamstring is effective in preventing lower extremity injuries (Basar et al., 2014). Several methods have been tried to increase the hamstring flexibility in previous studies (Bandy et al., 1997; Davis et al., 2005; Feland et al., 2001; Lim and Park, 2019). The majority of studies have compared different stretching types in terms of increasing the flexibility of the hamstring. Among these, proprioceptive neuromuscular facilitation techniques (Davis et al., 2005; Feland et al., 2001; Spernoga et al., 2001), static stretching (Bandy et al., 1997), and active dynamic stretching are the most preferred. Moreover, the different intensity and frequency of the use of these methods were also compared (Bandy et al., 1997).

Hamstring muscle injury is the most common sports injury, and the number of studies on this topic has increased considerably in recent years (Al Attar et al., 2017; Nishida et al., 2018; Volpi and Bisciotti, 2016) and decreased hamstring length and low flexibility are frequently observed in elite wrestlers (Callan et al., 2000) it is important to find a method to increase hamstring flexibility in wrestlers. Studies are available concerning neural sliding and neural stretching exercises enhancing hamstring flexibility (Ahmed and Samhan, 2016; Castellote-Caballero et al., 2013; CastelloteCaballero et al., 2014; Pagare et al., 2014; Park et al., 2014; Singh et al., 2017). Neural sliding is a neural mobilizing technique applied to the neural stem to slide the neural body in which one end of a neural stem is extended while the other end is relaxed (Ellis et al., 2012). Neural stretching is a neural mobilizing technique applied to the neural stem to stretch the neural body in which both ends of a neural stem are extended (Ellis et al., 2012). In the light of this information in the literature, we started our study with the hypothesis that the short-term effects of neural sliding and neural stretching exercises to the sciatic nerve on hamstring muscle length and functional flexibility will be similar. Although the effects of neural sliding and neural stretching exercises on hamstring flexibility have been investigated in healthy subjects (Sharma et al., 2016), the effect of neural mobilization exercises on functional flexibility and the effect on the athletes remains uncertain. Therefore, this study aimed to compare the short-term effects of neural sliding and neural stretching exercises on hamstring muscle length and functional flexibility applied to wrestlers.

\section{MATERIALS AND METHODS}

\section{Participants}

The study participants included 74 (15 females, 59 males) wrestlers who applied for performance measurements to the athlete training and health research center. Inclusion criteria were as follows: those who have an active knee extension (AKE) angle of $85^{\circ}$ or less, were a national wrestling athlete for at least 3 years, and volunteered to participate in the study. Exclusion criteria were individuals who had an acute or chronic orthopedic problem involving the lower extremity, a neurological problem, a history of neck trauma, existing hamstring injury or surgery, and back pain (Park et al., 2014; Sharma et al., 2016).

\section{Ethical approval}

All participants provided written assent or consent, and the coaches of participants aged $<18$ years provided written informed consent. The study was approved by a Training and Research Hospital's Ethics Committee Institutional Review Board (Ethics Committee Approval IRB study protocol:2012-KAEK-15/1609). We took permission from the National Wrestling Federation Presidency for using this data for the academic research with the number of TGF/1966.

Descriptive characteristics such as age, body mass index, sex, dominant extremity, and sport experience were recorded for the athletes included in the study (Table 1).

This study was conducted as a randomized controlled study. First, the descriptive information of the athletes who participated in the study was taken, and the AKE and the sit and reach test were evaluated. Then, the athletes included in the study were ran-

Table 1. Comparison of the demographic statistics of the groups

\begin{tabular}{lcccc}
\hline Variable & $\begin{array}{c}\text { Neural sliding } \\
\text { group }(\mathrm{n}=38)\end{array}$ & $\begin{array}{c}\text { Neural stretching } \\
\text { group }(\mathrm{n}=36)\end{array}$ & $t$ & $P$-value \\
\hline Age $(\mathrm{yr})$ & $17.86 \pm 2.31$ & $18.08 \pm 2.33$ & $0.397^{*}$ & $0.692^{*}$ \\
Height $(\mathrm{m})$ & $1.61 \pm 0.08$ & $1.63 \pm 0.06$ & $0.635^{*}$ & $0.528^{*}$ \\
Mass $(\mathrm{kg})$ & $66.89 \pm 16.93$ & $70.05 \pm 11.52$ & $0.933^{*}$ & $0.354^{*}$ \\
Body mass index $\left(\mathrm{kg} / \mathrm{m}^{2}\right)$ & $23.65 \pm 4.03$ & $26.63 \pm 2.81$ & $1.206^{*}$ & $0.232^{*}$ \\
Sex & & & $1.099^{\dagger}$ & $0.294^{\dagger}$ \\
$\quad$ Male & $32(84)$ & $27(75)$ & & \\
$\quad$ Female & $6(16)$ & $9(25)$ & & \\
Years of sport experience & $7.25 \pm 3.02$ & $6.6 \pm 2.6$ & $2.166^{\dagger}$ & $0.669^{\dagger}$ \\
Dominance & & & & \\
$\quad$ Right & $34(89)$ & $31(86)$ & & \\
Left & $4(11)$ & $5(14)$ & & \\
\hline
\end{tabular}

Values are presented as mean \pm standard deviation or number $(\%)$. ${ }^{*}$ Independent sample $t$-test. ${ }^{\dagger}$ Chi-square. 
domly divided into two groups (neural sliding and neural stretching groups) using the flip a coin method.

\section{Parameters}

AKE test

The AKE test was used to determine hamstring flexibility. In the test position, the athlete was laid down on the supine position, and the hip that was to be evaluated was taken $90^{\circ}$ in flexion and during the assessment, the ankle of this extremity was fixed $90^{\circ}$ in neutral position by the physiotherapist. The contralateral lower extremity was fixed as if it were a fully extended knee. The athlete was asked to bring his/her knee to the extension until he/she felt strong muscular resistance when the hip was in $90^{\circ}$ of flexion. During the exercise, rotations that could occur in the hip were not allowed. The goniometer pivot axis, placed in correspondence to the lateral femoral condyle and the stationary arm, was aligned along the femur and toward the trochanter major of the femur. The moving arm was held to follow the fibular body during the movement. The distance angle between the level attained by full knee extension $\left(180^{\circ}\right)$ and the level reached was recorded as active knee extension limitation (AKEL) angle. The test was performed 3 times, and the average of the scores was recorded (Hamid et al., 2013). The AKEL angle was evaluated for both limbs. The low score for this test indicates high hamstring flexibility.

\section{Sit and reach test}

A modified sit-reach test was used to assess functional flexibility. Baseline device (Cooper Institute/YMCA, AAHPERD; Fabrication Enterpriese, New York, NY, USA) was used for the sit and reach test. The athletes were instructed to place their heels in full contact on the tester when they sit in long sitting position and the ankle joint angle has been achieved to $90^{\circ}$ neutral position with the goniometer during assessment. After the arm length is determined on the device, they were instructed to reach out as far as possible without lifting their knees by pushing the device measurement apparatus forward with his/her fingertips. The distance between the starting and ending position was recorded in $\mathrm{cm}$. Measurements were taken 3 times and averaged values recorded (Wells and Dillon, 1952).

\section{Intervention}

Neural mobilization exercises were performed by a physiotherapist who was trained in neural mobilization to ensure safety and to make the practice effective. The outcome assessment and the obtainment of the data were performed by another physiothera- pist who was blinded to the neural mobilization groups. A specific intensity for the duration of neural mobilization exercises has not been defined in the literature. In the present study, neural stretching and neural sliding exercises were applied in 6 sets in total, including 3 sets for each extremity. Each set was completed in $60 \mathrm{sec}$, and a break of $30 \mathrm{sec}$ was taken between the sets. Exercises lasted 6 min in total for each athlete. AKEL angle and the sit and reach test were tested, respectively, immediately after the end of the exercises.

\section{Neural sliding group}

The sciatic nerve sliding exercise was performed in this study. The athletes were placed high in order not to touch their feet to the ground, with their hands holding on their backs. Exercise was performed in two stages. In the first stage, the athlete was asked to bring the cervical region of the extremity and the knee to the extension and to bring the ankle to dorsiflexion at the same time. In the second stage, after waiting for a second in the first stage, the athlete was asked to bring the cervical region into flexion with the head and neck flexion and bring the knee to the flexion and ankle to the plantar flexion at the same time. At every stage of the exercise, care was taken to protect the thoracolumbar region flexion (Ellis et al., 2012). One repetition was completed in $2 \mathrm{sec}$ in total, and a total of 30 repetitive exercises were performed in a set of $60 \mathrm{sec}$.

\section{Neural stretching group}

Neural stretching was performed in the same position as the neural sliding technique. Neural stretching exercise was performed in two stages. In the first stage, the athlete was asked to bring the cervical region into flexion and at the same time bring the knee to extension and the ankle to dorsiflexion. After waiting for one second in the first stage, the athlete was asked to restore ankle dorsiflexion by bringing the cervical region to the extremity and taking the knee flexion at the same time (Verrall et al., 2001). One repetition was completed in $2 \mathrm{sec}$ in total, and the exercise was performed in a set of $60 \mathrm{sec}$ with 30 repetitions. Similar to the neural sliding exercise, care was taken to protect the thoracolumbar region flexion.

\section{Statistical analysis}

Statistical analysis of the data obtained at the end of the study was performed via the IBM SPSS Statistics ver. 20.0 (IBM Co., Armonk, NY, USA). The variables were investigated using analytical methods (Kolmogorov-Smirnov/Shapiro-Wilk test) to de- 
termine whether the data were appropriate for normal distribution or not. Descriptive analyses were presented using means and standard deviation. The independent sample $t$-test was used to determine whether there was a significant difference between groups for data fit the normal distribution and chi-square test was used for categorical parameters. A three-way repeated-measures analysis of variance (ANOVA) was conducted that examined the effect of mobilization type (neural sliding and neural stretching), time (pre- and postmobilization), and gender (male and female) on interest in AKEL right leg, AKEL left leg, and sit and reach test. An overall $\% 5$ type-I error level was used to infer statistical significance.

\section{RESULTS}

No difference was observed between the descriptive data of the two groups $(P>0.05)$ (Table 1$)$. A three-way repeated-measures ANOVA results relieved that there is not a significant difference between the effect of two different mobilizations neural sliding and neural stretching on AKEL right leg, AKEL left leg, and sit and reach test $(P>0.05)$. It was determined there is statistically significant differences between premobilization and postmobilization outcome measures for AKEL right leg $(F=59.886, P=0.001)$, AKEL left leg $(F=31.896, P=0.001)$, and sit and reach test $(F=$ $22.630, P=0.001)$. There is not a statistically significant difference between males and females by these three measures (Table 2).

It was determined nonsignificant interactions between mobilization type and time, between mobilization type and gender, and between time and gender $(P>0.05)$. In other words, there are not statistically differences between mobilization types and between genders over time $(P>0.05)$. There is not a statistically difference between genders over mobilization types $(P>0.05)$. Besides, the three-way interaction between mobilization type, time and gender is not statistically significant $(P>0.05)$ (Table 2).

It was determined when the value of AKEL right leg and AKEL left leg values decrease over time; sit and reach test value increases in both gender by applying one of the two mobilization technique (Table 3).

Table 2. Three-way repeated measures ANOVA results

\begin{tabular}{|c|c|c|c|c|c|c|}
\hline \multirow{2}{*}{ Source } & \multicolumn{2}{|c|}{ AKEL right leg } & \multicolumn{2}{|c|}{ AKEL left leg } & \multicolumn{2}{|c|}{ Sit and reach test } \\
\hline & $F$ & $P^{\dagger}$ & $F$ & $P^{\dagger}$ & $F$ & $P^{\dagger}$ \\
\hline Mobilization type (neural sliding-neural stretching) & 0.596 & 0.443 & 0.643 & 0.425 & 1.860 & 0.177 \\
\hline Time (pre-post mobilization) & 59.886 & $0.001^{*}$ & 31.896 & $0.001^{*}$ & 22.630 & $0.001^{*}$ \\
\hline Gender (male-female) & 0.214 & 0.645 & 0.112 & 0.739 & 0.144 & 0.705 \\
\hline Mobilization type $\times$ time & 0.609 & 0.438 & 2.508 & 0.118 & 3.406 & 0.069 \\
\hline Mobilization type × gender & 0.015 & 0.903 & 0.038 & 0.846 & 3.828 & 0.054 \\
\hline Time $\times$ gender & 3.497 & 0.066 & 0.469 & 0.496 & 0.055 & 0.815 \\
\hline Mobilization type $\times$ time $\times$ gender & 1.831 & 0.180 & 1.700 & 0.197 & 2.414 & 0.125 \\
\hline
\end{tabular}

AKEL, active knee extension limitation.

${ }^{*} P<0.05{ }^{`}$ Three-way repeated measures analysis of variance (ANOVA).

Table 3. Mean values of the AKEL and sit and reach test result of the neural sliding and neural stretching groups

\begin{tabular}{|c|c|c|c|c|c|c|}
\hline \multirow{2}{*}{ Test } & \multicolumn{3}{|c|}{ Neural sliding group } & \multicolumn{3}{|c|}{ Neural stretching group } \\
\hline & Male $(n=27)$ & Female $(n=9)$ & Total $(n=36)$ & Male $(n=32)$ & Female $(n=6)$ & Total $(n=38)$ \\
\hline \multicolumn{7}{|c|}{ AKEL right leg } \\
\hline Pre- & $13.02 \pm 7.26$ & $14.30 \pm 4.42$ & $13.34 \pm 6.63$ & $11.61 \pm 6.28$ & $13.89 \pm 5.25$ & $11.97 \pm 6.12$ \\
\hline Post- & $9.64 \pm 6.28$ & $10.37 \pm 3.56$ & $9.82 \pm 5.68$ & $8.83 \pm 5.97$ & $7.72 \pm 3.16$ & $8.66 \pm 5.60$ \\
\hline \multicolumn{7}{|c|}{ AKEL left leg } \\
\hline Pre- & $13.67 \pm 7.41$ & $14.30 \pm 4.70$ & $13.82 \pm 6.78$ & $12.71 \pm 7.61$ & $14.06 \pm 4.52$ & $12.92 \pm 7.18$ \\
\hline Post- & $11.10 \pm 6.44$ & $12.41 \pm 4.41$ & $11.43 \pm 5.97$ & $9.83 \pm 5.79$ & $9.00 \pm 5.13$ & $9.70 \pm 5.63$ \\
\hline \multicolumn{7}{|c|}{ Sit and reach test } \\
\hline Pre- & $39.55 \pm 6.90$ & $35.03 \pm 6.64$ & $38.42 \pm 7.02$ & $38.69 \pm 5.68$ & $42.16 \pm 4.36$ & $39.24 \pm 5.59$ \\
\hline Post- & $41.99 \pm 5.96$ & $38.67 \pm 5.82$ & $41.16 \pm 6.02$ & $40.86 \pm 5.41$ & $42.68 \pm 4.59$ & $41.14 \pm 5.28$ \\
\hline
\end{tabular}

Values are presented as mean \pm standard deviation.

AKEL, active knee extension limitation. 


\section{DISCUSSION}

The results of the present study, which investigated the effects of neural sliding and neural stretching exercises of the sciatic nerve on the hamstring flexibility and functional flexibility, revealed that neural sliding and neural stretching exercises increase hamstring flexibility and functional flexibility, and that the effects of these two exercises are similar.

Moreover, both neural mobilization techniques (neural sliding and neural stretching) were found to enhance hamstring and functional flexibility. Compared with neural sliding and neural stretching exercises, they did not have a significant advantage over each other in terms of enhancement of AKE angle and functional flexibility. In this context, Ellis et al. (2012) who compared different mobilization exercises to the sciatic nerve, have identified that neural stretching and sliding mobilization are the two clinical exercises mostly releasing movement in the nerve bed. Additionally, this may be the reason why both exercises yielded the same result in the present study.

After neural mobilization exercises, there was a direct increase in hamstring flexibility with the increase in AKE angle. We think that this increased flexibility is achieved by neural mobilization exercises by providing more displacement of the sciatic nerve in the posterior thigh region (Ellis et al., 2012) and, as McHugh et al. (2012) suggested, by increasing the mobility of neural tissue and decreasing sensitivity. Functional flexibility was also increased by neural mobilization exercises. The mechanism of this increase may also be the same as the increase in the AKE. Another factor that contributes to the increase may be that the neural mobilization exercise position is similar to the functional sit and reach test.

Hamstring injuries are frequently seen in physically active individuals, especially in competition athletes (Safran et al., 1988). Athletes with reduced hamstring flexibility are at risk for possible hamstring injury (Hartig and Henderson, 1999). Optimal flexibility for a wrestling sport is a necessary parameter to demonstrate the relevant techniques better (Basar et al., 2014). Therefore, this study focused on wrestlers, as hamstring muscle shortness has been reported in wrestlers in the literature (Callan et al., 2000). It has been emphasized in the literature that there is little neural activity in individuals with hamstring shortness (Kujala et al., 1997). However, whether this diminishing mobility is due to intraneural factors (injury to the poststretch neural tissue) or extraneural factors (reduced neural motility resulting from muscle injury and adhesions) remains unclear (McHugh et al., 2012; Singh et al., 2017). Although previous studies have shown that hamstring flexibility is increased by mobilization of neural tissues, whether there is an increase in the motility of neural tissues is uncertain (CastelloteCaballero et al., 2013; Castellote-Caballero et al., 2014; O'Sullivan et al., 2009). Although there is not enough evidence, we think that an increase in the mobility of neural tissues simultaneously occurs with the increase in the hamstring length. Future studies are necessary to examine the long-term effect of neurodynamic exercises on neural activity.

The results of the present study support those of the previous studies (Herrington, 2006; Sharma et al., 2016). Sharma et al. (2016) concluded that in their study including 60 healthy participants, neural stretching and neural sliding exercises in addition to static stretching in hamstring were equally effective at increasing hamstring flexibility. Similarly, in another study comparing neural sliding and neural stretching exercises, no significant difference was found between the two mobilizations due to increasing knee extension angle. Castellote-Caballero et al. (2013) concluded that neural stretching exercises applied to healthy subjects for 1 week (3 days a week) were much more effective in increasing the range of motion of knee extension compared to those without any exercise. Studies comparing the exercise of neural mobilizations with different stretching methods in terms of hamstring flexibility are also available. In a study conducted with individuals with short hamstring, 120 people were divided into three groups: the first group performed static hamstring stretching; second group, neural sliding; and third group, mobilization of the talocrural joint as a placebo. More increased range of motion was obtained in the straight leg raise test in the group that performed neural sliding (CastelloteCaballero et al., 2014). Pagare et al. (2014), in their study, which included 30 male soccer players with hamstring shortness, have applied static stretching to 15 athletes and neural sliding exercises to 15 athletes for 3 days a week for a week, and both exercises have provided good results in the straight leg raise test.

This study has some limitations. No specific frequency and duration were defined in the literature for neural mobilizations. Different durations have been preferred in different studies (Ahmed and Samhan, 2016; Castellote-Caballero et al., 2013; CastelloteCaballero et al., 2014; Pagare et al., 2014; Park et al., 2014; Singh et al., 2017). In the present study, neural mobilization was applied in 3 sets of 60 -sec duration. Within these $60 \mathrm{sec}$, each athlete made a total of 90 repetitions for each leg, with about 30 repetitions of the exercise (Ellis et al., 2012). We think that this is a high number of repetitions and may have increased the flexibility of the hamstring by increasing the flexibility of nonneural structures such as the muscle and connective tissue. In this respect, our work can be 
regarded as the missing direction. However, because the same method is used for both groups, it is not a factor to change the effectiveness of the two different mobilizations.

In conclusion, neural sliding and neural stretching exercises applied to sciatic nerve in wrestlers were effective in increasing hamstring flexibility and functional flexibility and not superior to each other. Both procedures can be used clinically to improve hamstring flexibility and functional flexibility in athletes who have $<85^{\circ}$ AKE angle. This study shows the acute effect of neural sliding and neural stretching exercises. Therefore, it is recommended that neural sliding and neural stretching exercises should be used as an addition to routine warm-up programs and to increase precompetition flexibility.

\section{CONFLICT OF INTEREST}

No potential conflict of interest relevant to this article was reported.

\section{REFERENCES}

Ahmed AR, Samhan AF. Short term effects of neurodynamic stretching and static stretching techniques on hamstring muscle flexibility in healthy male subjects. Int J Med Res Health Sci 2016;5:36-41.

Al Attar WS, Soomro N, Sinclair PJ, Pappas E, Sanders RH. Effect of injury prevention programs that include the nordic hamstring exercise on hamstring injury rates in soccer players: a systematic review and meta-analysis. Sports Med 2017;47:907-916.

Arab AM, Abdollahi I, Joghataei MT, Golafshani Z, Kazemnejad A. Interand intra-examiner reliability of single and composites of selected motion palpation and pain provocation tests for sacroiliac joint. Man Ther 2009;14:213-221.

Bahr R, Holme I. Risk factors for sports injuries-a methodological approach. Br J Sports Med 2003;37:384-392.

Bandy WD, Irion JM, Briggler M. The effect of time and frequency of static stretching on flexibility of the hamstring muscles. Phys Ther 1997;77: 1090-1096

Basar S, Duzgun I, Guzel NA, Cicioğlu I, Çelik B. Differences in strength, flexibility and stability in freestyle and Greco-Roman wrestlers. J Back Musculoskelet Rehabil 2014;27:321-330.

Boyd BS, Wanek L, Gray AT, Topp KS. Mechanosensitivity of the lower extremity nervous system during straight-leg raise neurodynamic testing in healthy individuals. J Orthop Sports Phys Ther 2009;39:780790.

Callan SD, Brunner DM, Devolve KL, Mulligan SE, Hesson J, Wilber RL,
Kearney JT. Physiological profiles of elite freestyle wrestlers. J Strength Cond Res 2000;14:162-169.

Castellote-Caballero Y, Valenza MC, Martín-Martín L, Cabrera-Martos I, Puentedura EJ, Fernández-De-Las-Peñas C. Effects of a neurodynamic sliding technique on hamstring flexibility in healthy male soccer players. A pilot study. Phys Ther Sport 2013;14:156-162.

Castellote-Caballero Y, Valenza MC, Puentedura EJ, Fernández-De-LasPeñas C, Alburquerque-Sendín F. Immediate effects of neurodynamic sliding versus muscle stretching on hamstring flexibility in subjects with short hamstring syndrome. J Sports Med (Hindawi Publ Corp) 2014;2014:127471.

Croisier JL. Factors associated with recurrent hamstring injuries. Sports Med 2004;34:681-695.

Davis DS, Ashby PE, McCale KL, McQuain JA Wine JM. The effectiveness of 3 stretching techniques on hamstring flexibility using consistent stretching parameters. J Strength Cond Res 2005;19:27-32.

De-La-Llave-Rincon AI, Ortega-Santiago R, Ambite-Quesada S, Gil-Crujera A, Puentedura EJ, Valenza MC, Fernández-De-Las-Peñas C. Response of pain intensity to soft tissue mobilization and neurodynamic technique: a series of 18 patients with chronic carpal tunnel syndrome. J Manipulative Physiol Ther 2012;35:420-427.

Ellis RF, Hing WA, McNair PJ. Comparison of longitudinal sciatic nerve movement with different mobilization exercises: an in vivo study utilizing ultrasound imaging. J Orthop Sports Phys Ther 2012;42:667-675.

Feland JB, Myrer J, Merrill R. Acute changes in hamstring flexibility: PNF versus static stretch in senior athletes. Phys Ther Sport 2001;2:186-193.

Hall T, Zusman M, Elvey R. Adverse mechanical tension in the nervous system? Analysis of straight leg raise. Man Ther 1998;3:140-146.

Hamid MSA, Ali MRM, Yusof A. Interrater and intrarater reliability of the active knee extension (AKE) test among healthy adults. J Phys Ther Sci 2013;25:957-961.

Hartig DE, Henderson JM. Increasing hamstring flexibility decreases lower extremity overuse injuries in military basic trainees. Am J Sports Med 1999;27:173-176.

Heiderscheit BC, Sherry MA, Silder A, Chumanov ES, Thelen DG. Hamstring strain injuries: recommendations for diagnosis, rehabilitation, and injury prevention. J Orthop Sports Phys Ther 2010;40:67-81.

Herrington L. Effect of different neurodynamic mobilization techniques on knee extension range of motion in the slump position. J Man Manip Ther 2006;14:101-107.

Kornberg C, Lew P. The effect of stretching neural structures on grade one hamstring injuries. J Orthop Sports Phys Ther 1989;10:481-487.

Kujala UM, Orava S, Järvinen M. Hamstring injuries. Sports Med 1997;23: 397-404.

Lim JH, Park CB. The immediate effects of foam roller with vibration on 
hamstring flexibility and jump performance in healthy adults. J Exerc Rehabil 2019;15:50-54.

Marshall PW, Cashman A, Cheema BS. A randomized controlled trial for the effect of passive stretching on measures of hamstring extensibility, passive stiffness, strength, and stretch tolerance. J Sci Med Sport 2011; 14:535-540.

Mchugh M, Johnson C, Morrison R. The role of neural tension in hamstring flexibility. Scand J Med Sci Sports 2012;22:164-169.

Nishida S, Tomoto T, Maehara K, Miyakawa S. Acute effect of low-intensity eccentric exercise on angle of peak torque in subjects with decreased hamstring flexibility. Int J Sports Phys Ther 2018;13:890-895.

O'sullivan K, Murray E, Sainsbury D. The effect of warm-up, static stretching and dynamic stretching on hamstring flexibility in previously injured subjects. BMC Musculoskelet Disord 2009;10:1-9.

Pagare VK, Ganacharya PM, Sareen A, Palekar TJ. Effect of neurodynamic sliding technique versus static stretching on hamstring flexibility in football players with short hamstring syndrome. J Musculoskelet Res 2014;17:1450009.

Park JM, Cha JY, Kim HJ, Yasuyoshi A. Immediate effects of a neurodynamic sciatic nerve sliding technique on hamstring flexibility and postural balance in healthy adults. Phys Ther Rehab Sci 2014;3:38-42.

Park KJ, Lee JH, Kim, HC. Injuries in male and female elite Korean wrestling athletes: a 10-year epidemiological study. Br J Sports Med 2019; 53:430-435.

Petersen W, Ellermann A, Gösele-Koppenburg A, Best R, Rembitzki IV, Brüggemann GP, Liebau C. Patellofemoral pain syndrome. Knee Surg Sports Traumatol Arthrosc 2014;22:2264-2274.

Safran MR, Garrett JR WE, Seaber AV, Glisson RR, Ribbeck BM. The role of warmup in muscular injury prevention. Am J Sports Med 1988;16: 123-129.
Sharma S, Balthillaya G, Rao R, Mani R. Short term effectiveness of neural sliders and neural tensioners as an adjunct to static stretching of hamstrings on knee extension angle in healthy individuals: a randomized controlled trial. Phys Ther Sport 2016;17:30-37.

Singh AK, Nagaraj S, Palikhe RM, Neupane B. Neurodynamic sliding versus PNF stretching on hamstring flexibility in collegiate students: a comparative study. Int J Phys Educ Sports Health 2017;1:29-33.

Spernoga SG, Uhl TL, Arnold BL, Gansneder BM. Duration of maintained hamstring flexibility after a one-time, modified hold-relax stretching protocol. J Athl Train 2001;36:44-48.

Tafazzoli F, Lamontagne M. Mechanical behaviour of hamstring muscles in low-back pain patients and control subjects. Clin Biomech 1996;11: 16-24.

Turl SE, George KP. Adverse neural tension: a factor in repetitive hamstring strain? J Orthop Sports Phys Ther 1998;27:16-21.

Van Der Worp H, Van Ark M, Roerink S, Pepping GJ, Van Den AkkerScheek I, Zwerver J. Risk factors for patellar tendinopathy: a systematic review of the literature. Br J Sports Med 2011;45:446-452.

Verrall G, Slavotinek J, Barnes P, Fon G, Spriggins A. Clinical risk factors for hamstring muscle strain injury: a prospective study with correlation of injury by magnetic resonance imaging. Br J Sports Med 2001; 35:435-439.

Volpi P, Bisciotti GN. The hamstring muscles: anatomy, biomechanics and risk injury. Med Sports 2016;69:297-307.

Wells KF, Dillon EK. The sit and reach-a test of back and leg flexibility. Res Q Am Assoc Health Phys Educ 1952;23:115-118.

Witvrouw E, Danneels L, Asselman P, D'have T, Cambier D. Muscle flexibility as a risk factor for developing muscle injuries in male professional soccer players: a prospective study. Am J Sports Med 2003;31:41-46. 